\title{
Seismic monitoring and vibrational characterization of small wind turbines: A case study of the potential effects on the Eskdalemuir International Monitoring System Station in Scotland
}

\author{
Rachel F. Westwood*, Peter Styles and Samuel M. Toon \\ Applied and Environmental Geophysics Research Group, Keele University, Keele, Staffordshire, ST5 5BG, UK
}

Received March 2014, revision accepted October 2014

\begin{abstract}
This paper presents a case study of the ground-borne vibrations generated by small wind turbines. This is of particular importance for assessing the possible impact on the detection capabilities of the International Monitoring System seismic array at Eskdalemuir in Scotland. Measurements were gathered from a selection of small wind turbines $(\leq 50 \mathrm{~kW})$, from three different manufacturers, varying in hub height, power and construction using a range of accelerometers and seismometers fixed to the tower and buried in the adjacent ground at increasing distances. Previous studies have shown that medium and large turbines generate harmonic vibrations. Planning guidelines exist but have inadvertently led to a ban on the deployment of individual small-turbines within $50 \mathrm{~km}$ of the array. This study investigates whether their inclusion in these guidelines is necessary.

Vibration levels on the tower are in the region of $10^{-3} \mathrm{~m} / \mathrm{sqrt}(\mathrm{Hz})$, are transferred into the ground and decay rapidly away from the turbine $\left(10^{-5} \mathrm{~m} / \mathrm{sqrt}(\mathrm{Hz})\right.$ in the ground at $\left.200 \mathrm{~m}\right)$. The spectral content of the vibrations shows variations between the turbines, but each have peaks in the band of interest for Eskdalemuir. Further, sources of the peaks in the spectra are identified as either originating from the blades' rotation or the resonant modes of the turbines.

Analysis of the relationship between wind speed and seismic amplitude on the tower shows an exponential trend, individual to each wind turbine and the frequency band of interest. Similarly, analysis of the seismic amplitude between the tower and foundation shows that this can be described by a power law, but this is individual to each turbine. It is our opinion that there is little requirement to include turbines of $50 \mathrm{~kW}$ or less in planning guidelines outside the statutory exclusion zone of $10 \mathrm{~km}$, but each turbine should be considered on an individual basis.
\end{abstract}

\section{INTRODUCTION}

Renewable energy sources, especially wind power, have become a focus of energy policies in many countries. The small wind market, that is wind turbines with a rated power of less than 50 $\mathrm{kW}$, has seen particularly strong growth across the world with global capacity, according to the World Wind Energy Association, totalling more than $576 \mathrm{MW}$. This is expected to increase with a forecast of an additional $1000 \mathrm{MW}$ of new capacity being installed annually by 2020 , which would provide a cumulative total of $5 \mathrm{GW}$ of installed worldwide capacity (Gsänger 2013).

By design, wind turbines have to be located at sites with high wind speeds. This leads to high forces acting upon the tower and the blades, causing vibrations throughout the structure. Some of these can be detrimental to the turbine, whilst others are trans-

*r.f.westwood@keele.ac.uk ferred into the ground and can propagate to distances of $10 \mathrm{~km}$ or more (Styles et al. 2005).

Current literature specifically focusses on vibrations of the wind turbine blades (Liu 2013; Yang and Sun 2013; Skrzypiński and Gaunaa 2014; Zhou et al. 2014); the gearbox (Zhang et al. 2012); and the effect of earthquakes and seismic activity on the turbine (Díaz and Suárez 2013; Taddei and Meskouris 2014). Additionally, there is considerable research in the field of low frequency noise and infrasound from wind turbines (Jakobsen 2005; Pedersen and Waye 2008; Dijkstra and Kerkers 2011; Guarnaccia et al. 2011; Møller and Pedersen 2011; Taylor et al. 2013; de Beer 2013; Mollasalehi et al. 2013; Larsson and Öhlund 2014). However, there is limited work available which examines how low frequency vibrations from wind turbines affect the surrounding ground and nearby structures, and all focus on large wind turbines (Legerton et al. 1996; Schofield 
2002; Styles et al. 2005; Fiori et al. 2009; Saccorotti et al. 2011).

This paper looks at the results of monitoring the vibrations from four small wind turbines located at sites around the UK (Fig. 1) and varying in rated power, tower height and construction. A case study focussed on the Eskdalemuir seismological array (station code EKA) in Scotland is used to demonstrate whether the vibrations could affect the listening capabilities of the station, which is a component of the International Monitoring System (IMS) for the Comprehensive Nuclear-Test Ban Treaty (CTBT).

This work aims to characterise the spectral characteristics of small wind turbines, so that they could be included in operational planning requirements for wind farm development in the Scottish Southern Uplands. This would probably be operated in a generic manner and has already been adopted for larger wind turbines. The decisions on planning permission are from a huge range of site locations where the specific site geology is unlikely to be known, as that is not part of the planning procedure.

Following this introduction, the paper provides an overview of the EKA array, detailing why this site is a good case study to use. This is followed by an explanation of the data acquisition and processing techniques and then details of each of the turbines and study sites. In order to assess whether each of the turbines would generate frequencies in the $4-5 \mathrm{~Hz}$ band, critical for EKA, the spectral characteristics are analysed and the sources of key frequencies identified. Previous studies (Styles et al. 2005; Saccorotti et al. 2011) have found that wind speed can affect the amplitude of the signal from large wind turbines. Therefore this, along with the relationship between seismic amplitude on the tower and foundation, are investigated for small wind turbines.

\section{PREVIOUS STUDIES}

Very few studies on the microseismic vibrations from wind farms have been carried out in either the UK or abroad. The first work was in the early 1990s by Legerton et al. (1996) at St Breock Downs in Cornwall, UK, a wind farm consisting of eleven Bonus $450 \mathrm{~kW}$ turbines. The study found that harmonic components of a prominent $0.5 \mathrm{~Hz}$ peak in the spectra were transmitted through the ground with particular peaks occurring at $0.5 \mathrm{~Hz}, 3 \mathrm{~Hz}$, $4.5 \mathrm{~Hz}, 6 \mathrm{~Hz}$ and $7.5 \mathrm{~Hz}$, as well as higher frequencies. The amplitudes of these frequencies were found to differ with wind speed, with different frequencies being more dependent on different wind speeds.

This was followed by work in the USA by Schofield (2002) to determine whether the seismic signals from the proposed large (300 turbines) Maiden wind project would be detrimental to the Laser Interferometric Gravitational Wave Observatory (LIGO) on the Hanford Reservation. The study focused on measurements of the vibrations from the Stateline Wind Project in Oregon, which consisted of 399 Vestas V47, $660 \mathrm{~kW}$ wind turbines and found results consistent with Legerton et al. (1996). Schofield (2002) identified peaks which increased in frequency as the rota-

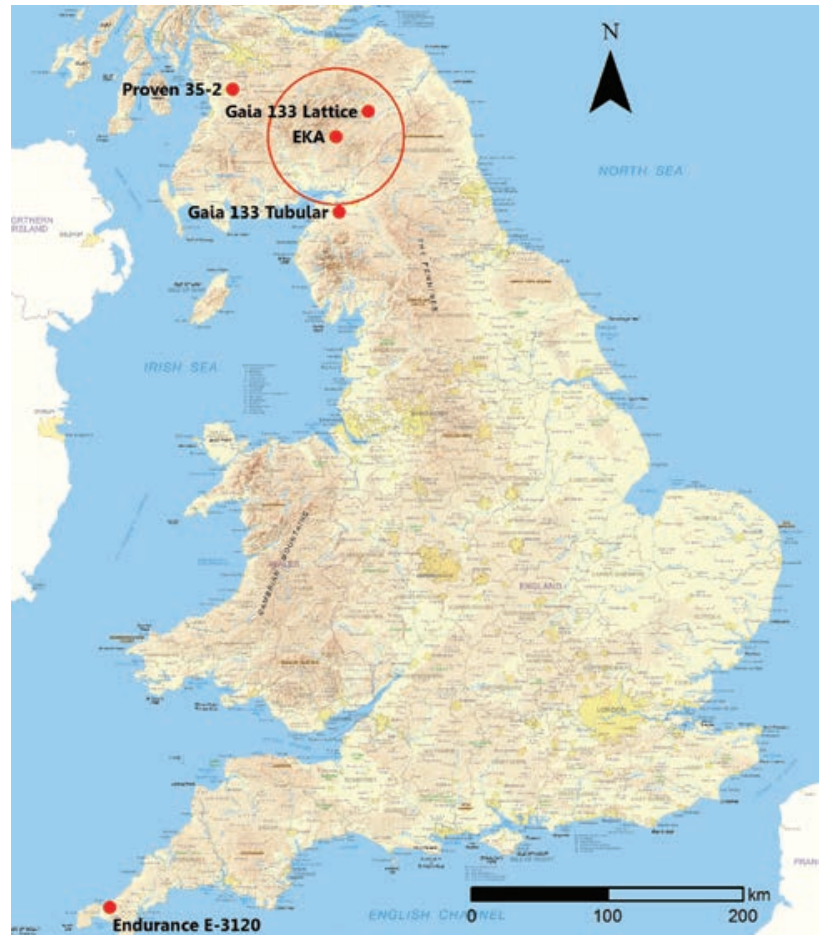

FIGURE 1

Locations of each of the wind turbine sites, the Eskdalemuir array (EKA) and $50 \mathrm{~km}$ consultation zone.

tional rate of the turbines increased, before stabilising at high wind velocities when the turbines run at a nearly constant rotational rate. Similarly to the previous work, prominent frequencies were identified as harmonic components of the blade passing frequency of $0.49 \mathrm{~Hz}$.

In 2004, work was carried out to investigate the nature and levels of vibration from wind turbines and whether these would interfere with EKA. The study (Styles et al. 2005; England, 2007) focused on twenty-six Vestas V47 $660 \mathrm{~kW}$ turbines, the same model of turbine as studied by Schofield (2002), and situated on similar geology and topography to Eskdalemuir (Silurian Shales). Ten seismometers were deployed at locations up to $17 \mathrm{~km}$ away from the wind farm for a period of four months. The study found that the spectral content of the signal contained prominent frequencies in the $4-5 \mathrm{~Hz}$ band, critical to EKA.

Each of the above studies consisted of a shut-down phase where it was consistently found that the amplitude of the frequency spectrum from measurements recorded on the turbine clearly dropped, but the resonant frequencies were still visible, although at a much lower amplitude.

Fiori et al. (2009) carried out work in 2005 at the Schliekum wind farm near the Gravitational Wave Observatory (GEO600), located $25 \mathrm{~km}$ south of Hannover, with the aim of generating a model to predict the effect of a wind farm planned for construction close to the Virgo gravitational wave detector near Pisa, Italy. Their results show that the general amplitude of the spec- 
trum increases with wind speed and that even when the turbine is not operational, some peaks are still visible, agreeing with the findings of Legerton et al. (1996) and England (2007). The proposed farm was installed by mid-2008 and plans had been submitted for an additional three 2 MW turbines. In 2009, Saccorotti et al. (2011) conducted measurements at Virgo to determine the nature and attenuation of the seismic signals from the existing wind farm and found results consistent with previous studies.

These studies have all shown that large wind turbines generate low frequency vibrations which are propagated many kilometres through the ground. However, the frequencies that are generated are not consistent through all turbine types. What makes this case study relevant is that no previous studies considered vibrations from small wind turbines.
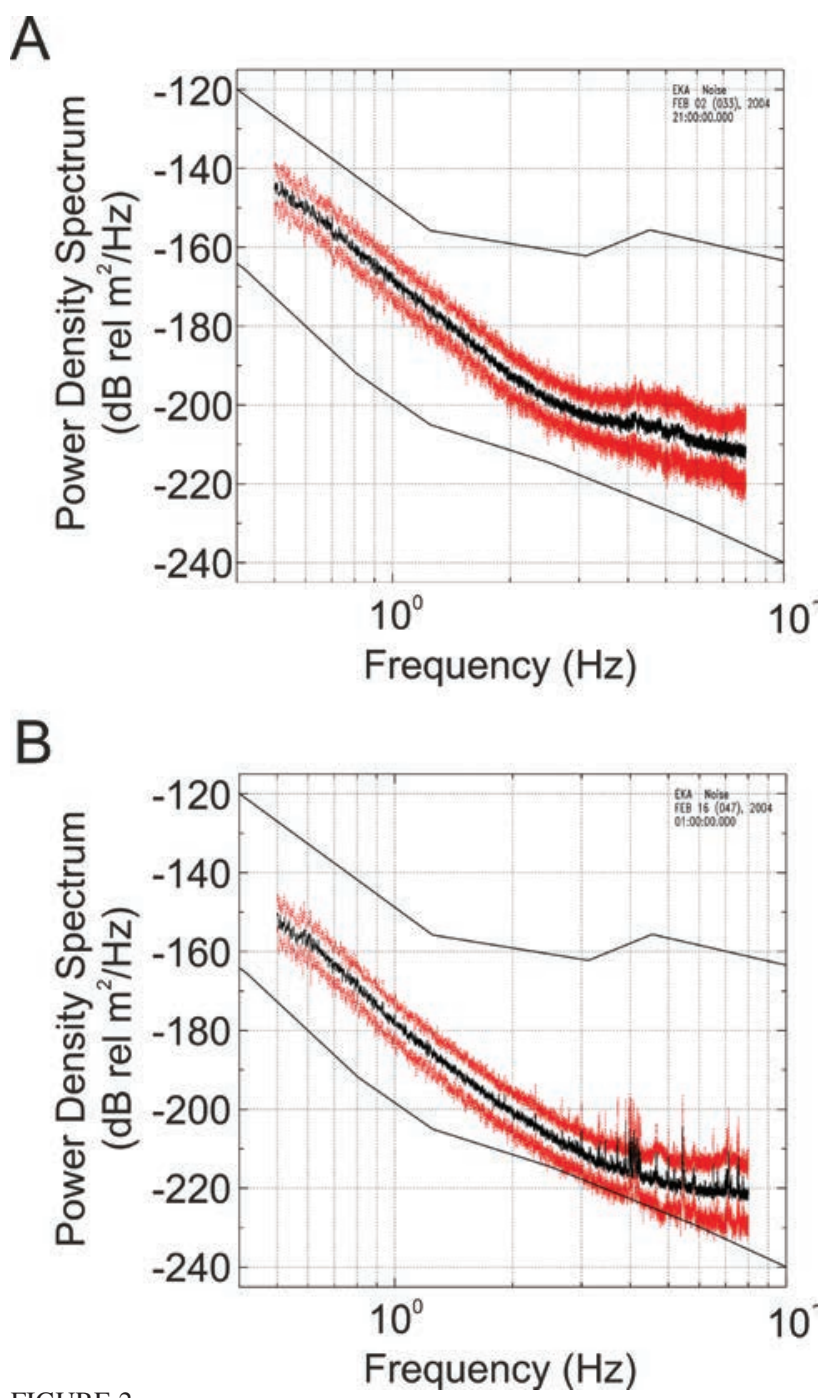

FIGURE 2

Power spectra from EKA at $12.86 \mathrm{~m} / \mathrm{s}$ wind speed (A) and $0 \mathrm{~m} / \mathrm{s}$ wind speed (B). The red lines are \pm two standard deviations from the mean (central black line). The outer black solid lines indicate the high and low noise models of Peterson (1993). After Bowers (2004).

\section{ESKDALEMUIR SITE DESCRIPTION}

Operational since May 1962 and situated between Moffat and Hawick in the Scottish Southern Uplands, EKA is an integral component of the IMS, an element of the verification regime for the CTBT. The UK is bound by the terms of the treaty to ensure the detection capabilities of the station are not compromised. The length of operation and geometry of the array (twenty broadband seismometers arranged in two almost perpendicular arms over 10 $\mathrm{km}$ with ten seismometers in each (Truscott 1964)) means that EKA is the longest serving steerable seismic array in the world. The array has the ability to record not just local signals (e.g. road traffic, wind, oceans, wind farms) but also signals which originate several thousands of kilometres away, including explosions and earthquakes. Over 400 signals associated with nuclear explosions have been recorded at EKA. The site is one of the seismically quietest in the UK and it has been shown by Elliot et al. (2004) that at windy times the seismic noise, above $2 \mathrm{~Hz}$, is only $20 \mathrm{~dB}$ above the Peterson (1993) low-noise model and at quiet times less than $10 \mathrm{~dB}$ above the low-noise model (Fig. 2).

The work by Styles et al. (2005) showed that the vibrations generated by large wind turbines have a spectral content containing prominent frequencies in the 4-5 Hz band, a frequency band which is seismically very quiet at EKA and critical to the stations detection capabilities, lying in the centre of its $0.5-8 \mathrm{~Hz}$ pass band of interest (Bowers 2004; Styles et al. 2005). The frequency band is also seen to be generated by similar power turbines in experiments by Legerton et al. (1996) and Schofield (2002). As a consequence of the work, a $50 \mathrm{~km}$ radius consultation zone centred on EKA was implemented by the UK Ministry of Defence for all new wind turbine developments. A model was derived to calculate the aggregate vibrational contribution from any planned wind farm in the vicinity of EKA. A threshold value was obtained using the median value of 330 half hour data sets of seismic background noise levels at wind speeds greater than $12.8 \mathrm{~m} / \mathrm{s}$ recorded on the array. A maximum permissible aggregate background noise budget of $0.336 \mathrm{~nm}$ was introduced to allow wind turbine developments in the zone to a level that would not interfere with the detection capabilities of the station. This is the model currently in use by the UK Ministry of Defence to assess whether an objection should be raised for planning applications within the consultation zone. No distinctions are made between different types of wind turbines based on rated power output or hub height.

Since the time of the Styles study, wind farm development in the area has increased and the noise budget is close to capacity. This has led to a total ban by the UK Ministry of Defence on all new developments within the zone, including small $(\leq 50 \mathrm{~kW})$ wind turbines.

There are over ten manufacturers of small wind turbines in the UK and more abroad. In recent years, demand for small and medium (50-500 kW) wind turbines has increased considerably, with RenewableUK reporting that deployed capacity in the UK reached over $100 \mathrm{MW}$ at the end of 2012, an increase of $71 \%$ on 
TABLE 1

Specifications of each of the wind turbines.

\begin{tabular}{lccc}
\hline Manufacturer and Model & Power $(\mathbf{k W})$ & Tower height $(\mathbf{m})$ & Rotor diameter $(\mathbf{m})$ \\
\hline MEL - Gaia-Wind 133 (lattice tower) & 11 & 18 & 13 \\
WIG - Gaia-Wind 133 (tubular tower) & 11 & 18 & 13 \\
KIL - Proven 35-2 & 12.1 & 15 & 8.5 \\
HAY - Endurance E-3120 & 50 & 24 & 19.2 \\
\hline
\end{tabular}

the previous year. Therefore, this paper is important for assessing the impact that the increasing numbers of small wind turbine installations may have on sensitive scientific installations not only in the UK, but around the World and will use the Eskdalemuir seismological station as a case study.

\section{DATA ACQUISITION AND PROCESSING}

A combination of sensors was deployed at each site, selected from the following instrument pool:

- 1x Guralp CMG-6TD three-component broadband seismometer;

- 1x Guralp CMG-5TD three-component accelerometer;

- 6x Guralp CMG-5U single-component accelerometers;

- 1x Guralp CMG-DM24S6EAM six channel digitiser;

- 1x anemometer on a 4 m mast.

The instrument selection depended upon the site layout, equipment availability and the combination that provided the best resolution for both directional and attenuation measurements over a wide frequency band and distancing range. All sensors were set to the same sampling rate of $200 \mathrm{~Hz}$ on each channel and recordings were carried out over a seven day period. The sensors were deployed in the same way at each site.

The CMG-6TD was deployed, in line with Seis-UK's recommended field deployment guidelines (Brisbourne et al. 2013), in a hole $80-100 \mathrm{~cm}$ deep and $30 \mathrm{~cm}$ in diameter. A layer of clean sand approximately $2 \mathrm{~cm}$ deep is placed at the bottom and gently firmed down in order to provide a platform in which to level the sensor and hold it in place. To protect it from very wet conditions, the sensor was placed in plastic bags and sealed. The sensor is levelled by firmly pushing downward, and aligned North-South before the pit is backfilled with sand and tamped a little at a time to the top of the sensor. The CMG-5TD was deployed in the same manner.

Two CMG-5U accelerometers were attached horizontally and perpendicularly on the tower, using magnets. A third accelerometer was attached horizontally to the foundation of the turbine. At three of the sites (WIG, MEL and HAY), further accelerometers were buried in the ground, in pits approximately $30-50 \mathrm{~cm}$ deep and lined with builders' sand, in a similar manner to the CMG6TD and placed in a radial line at $10 \mathrm{~m}, 20 \mathrm{~m}$ and $30 \mathrm{~m}$ from the wind turbine. These, combined with the sensor on the foundation, measured the radial component.

\section{DATA PROCESSING}

The anemometer was attached to a $4 \mathrm{~m}$ high mast. As this was not representative of the turbine height, the wind speed was corrected to represent an estimate of the wind speed at hub height using equation (1) for wind shear, taken from Manwell et al. (2009).

$v=v_{0}\left(\frac{\ln (h / z)}{\ln \left(h_{0} / z\right)}\right)$,

where $v_{0}$ is the measured wind speed at height $h_{0}, v$ is the predicted wind speed at height $h$ and $z$ is the surface roughness length. There is an element of error to this calculation as $z$ may change depending upon wind direction and site conditions.

Prior to processing, all seismic data was converted to acceleration, using the calibration data provided by Guralp and differentiated, if appropriate. The data was processed in the same manner for each turbine using a three-step method:

1. The data was split into 10 minute blocks, correlating to the wind speed reading times;

2. An acceleration power spectral density (PSD) function was calculated for each block using the Welch (1967) method:

a. Split the samples into $M$ overlapping segments, each with length $L$ and $D$ samples apart, such that

$(M-1) D+L=N$.

b. Each of the $M$ samples is windowed using data windows $W(\xi)$, for $\square=0 \ldots \mathrm{L}-1$ and the Finite Fourier Transform performed on the sequences $X_{l}(\square) W(\square) \ldots X_{M}(\square) W(\square)$ to obtain $B_{1}(n) \ldots B_{M}(n)$. The $M$ periodograms are obtained using,

$B_{m}(n)=\frac{1}{L} \sum^{L-1} X_{M}(\xi) W(\xi) e^{-\frac{2 m i \xi n}{L}}$

where $m=1 . . . M$ and $n=0 \ldots L / 2$.

c. The spectrum is an average of the periodograms,

$\hat{I}_{k}\left(\frac{N}{L}\right)=\frac{1}{M} \sum_{m=0}^{M} \frac{L}{U}\left|B_{m}(n)\right|^{2}$,

where,

$U=\frac{1}{L} \sum_{\xi=0}^{L-1} W^{2}(\xi)$

The result is an array of power plots $(\mathrm{dB})$ vs frequency (Hz).

3. Displacement spectral plots were generated by integration using equation (2).

$S_{d}(f)=\frac{S_{a}(f) / 4 \pi^{2} f^{2}}{4 \pi^{2} f^{2}}=\frac{S_{a}(f)}{16 \pi^{4} f^{4}}$, 
where $S_{d}(f)$ is the desired displacement PSD, $S_{a}(f)$ is the acceleration PSD and $f$ is the frequency.

An interquartile mean was used to calculate an average PSD over a range of wind speeds, in order to reduce the effects of outliers on the calculated average.

\section{THE WIND TURBINES AND STUDY SITE LOCATIONS}

Four small wind turbines (Table 1) were chosen to represent the overall variation in design, power and operation of small wind turbines.

\section{Gaia-Wind 133 (Tubular tower): Wigton, Cumbria, England (WIG)}

The Gaia-Wind $13311 \mathrm{~kW}$ wind turbine was developed in Denmark in the early 1990s, with the first turbine going operational in 1993. Unlike most wind turbines, the Gaia-Wind only has two blades, which rotate at a fixed speed of $56 \mathrm{rpm}$ and are attached to a unique teeter hub. The turbine has a rotor diameter of $13 \mathrm{~m}$ and generates power at wind speeds between $3.5 \mathrm{~m} / \mathrm{s}$ and $25 \mathrm{~m} / \mathrm{s}$. The turbine is available at two heights of $18 \mathrm{~m}$ or $27 \mathrm{~m}$

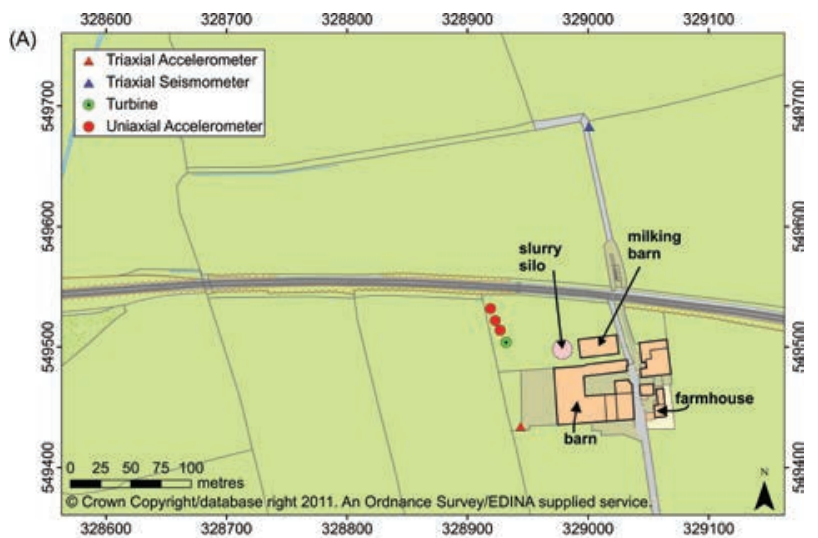

(B)

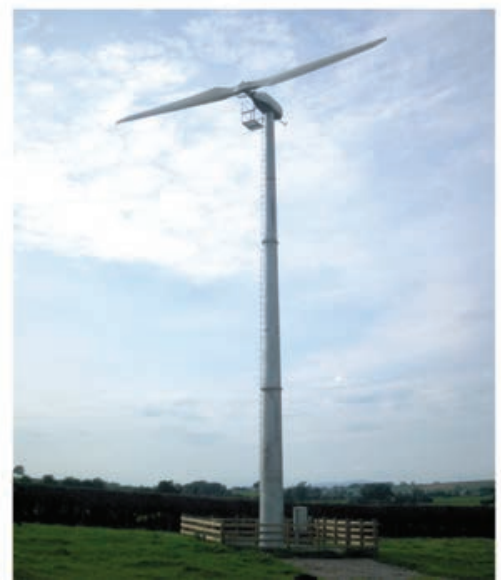

FIGURE 3

The Gaia-Wind 133 Tubular wind turbine test site details. A) The site at Wigton, Cumbria, in England. The map shows the location of the sensors in relation to the wind turbine and nearby buildings. B) The Gaia-Wind 133 tubular tower wind turbine. on a tubular monopole tower. The former was monitored for this study. The turbine sits on a foundation of reinforced concrete, set in soil, with dimensions of $5 \mathrm{~m} \times 5 \mathrm{~m} \times 0.5 \mathrm{~m}$.

There is an anemometer connected to the upwind side of the nacelle, which is used for monitoring the wind speed at hub height and controlling the operation of the turbine but the values are not logged.

This turbine is situated on private land at a farm just outside the village of Wigton in Cumbria, $13 \mathrm{~km}$ south-west of Carlisle and outside the Eskdalemuir exclusion zone. The turbine powers a dairy farm and is located in a field to the rear of the property. It lies north-west of the main farm building and approximately $40 \mathrm{~m}$ from the Carlisle to Barrow-on-Furness rail line (Fig. 3).

\section{Gaia-Wind 133 (Lattice tower): Melrose, Scottish Borders, Scotland (MEL)}

The Gaia-Wind 133 (lattice tower) wind turbine (Fig. 4) has the same foundation, power, rotation speed, blades and hub as the tubular tower Gaia-Wind 133. The main difference between the two is the tower design and height. The lattice tower is availa-

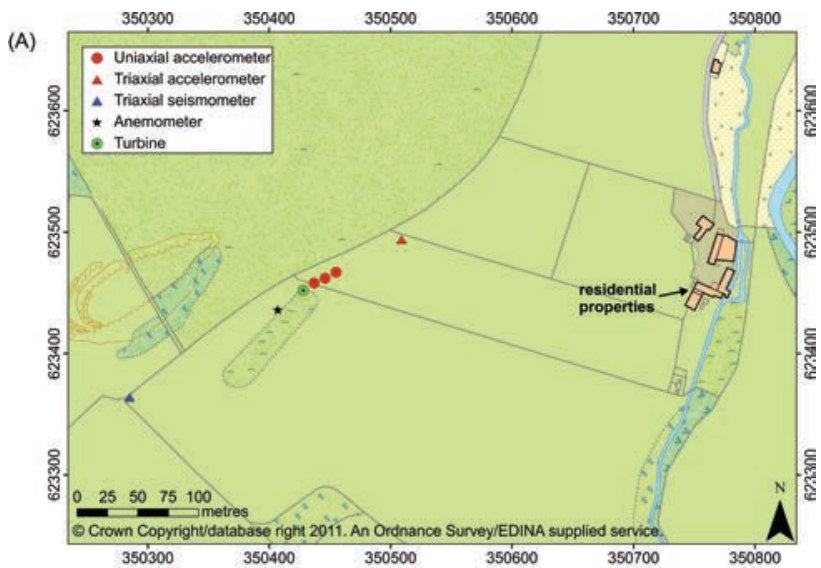

(B)

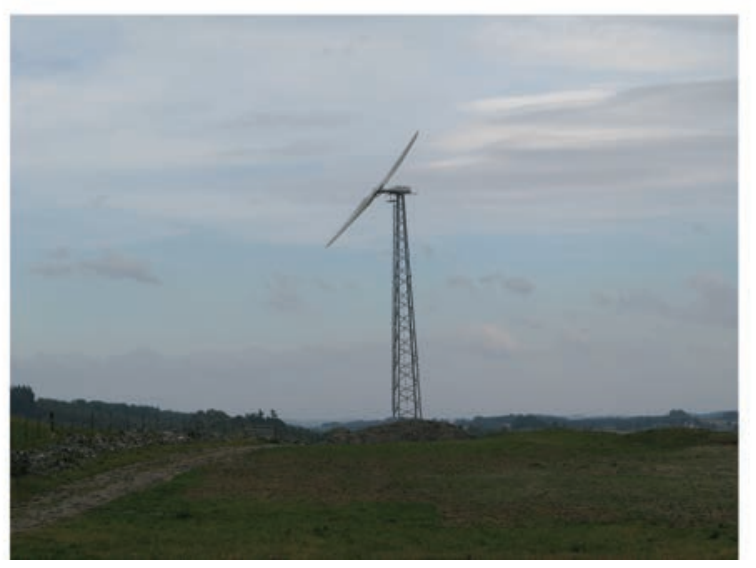

FIGURE 4

The Gaia-Wind 133 Lattice wind turbine test site details. A) The site at Melrose in the Scottish Borders. The map shows the location of the sensors in relation to the wind turbine and nearby buildings. B) The GaiaWind 133 lattice tower wind turbine. 
(A)

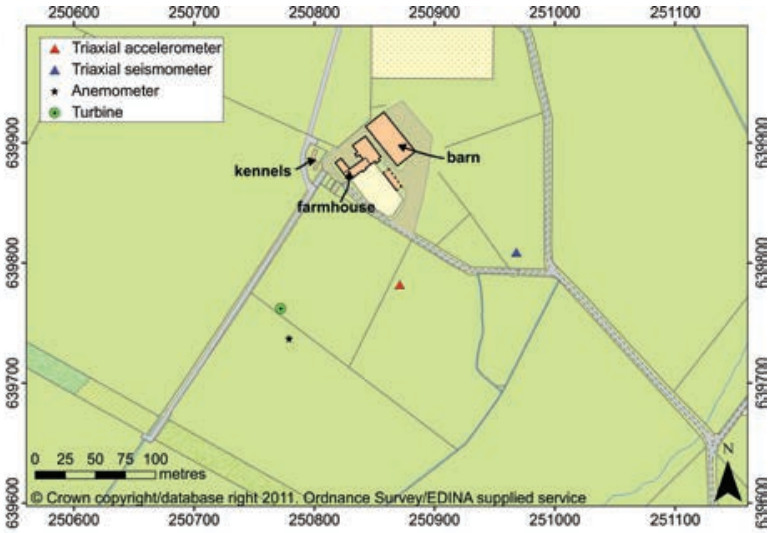

(B)

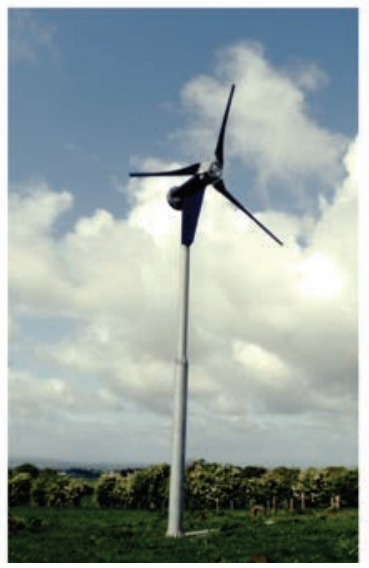

FIGURE 5

The Proven 35-2 wind turbine test site details. A) The site at Kilmarnock, Ayrshire in Scotland. The map shows the location of the sensors in relation to the wind turbine and nearby buildings. B) The Proven 35-2 wind turbine.

ble in two heights of $15 \mathrm{~m}$ and $18 \mathrm{~m}$, with the latter monitored for this study. This turbine is situated on private property, inside the Eskdalemuir consultation zone near Melrose in the Scottish Borders, $6 \mathrm{~km}$ south-east of Selkirk. It is on the top of a hill away from any buildings, more than a kilometre away from the nearest minor road and over $3 \mathrm{~km}$ from the nearest main road, the A7.

\section{Proven 35-2: Kilmarnock, Ayrshire, Scotland (KIL)}

The Proven $35-212 \mathrm{~kW}$ wind turbine is a three-blade machine and at the time of monitoring was the most popular of the three turbines sold by Proven. Unlike the Gaia-Wind 133 and the Endurance E-3120, the Proven turbine is self-regulating. The blades pitch and cone to regulate the speed. It has a rotor diameter of $8.5 \mathrm{~m}$ and operates at wind speeds between $3.5 \mathrm{~m} / \mathrm{s}$ and $54 \mathrm{~m} / \mathrm{s}$. The direction in which the blades face is controlled by a rudder made from a glass thermoplastic composite which fits over the hub and round the top section of the tower. The turbine sits on a foundation of reinforced concrete, in soil, with dimensions of $3.7 \mathrm{~m} \times 3.7 \mathrm{~m} \times 1.2 \mathrm{~m}$.
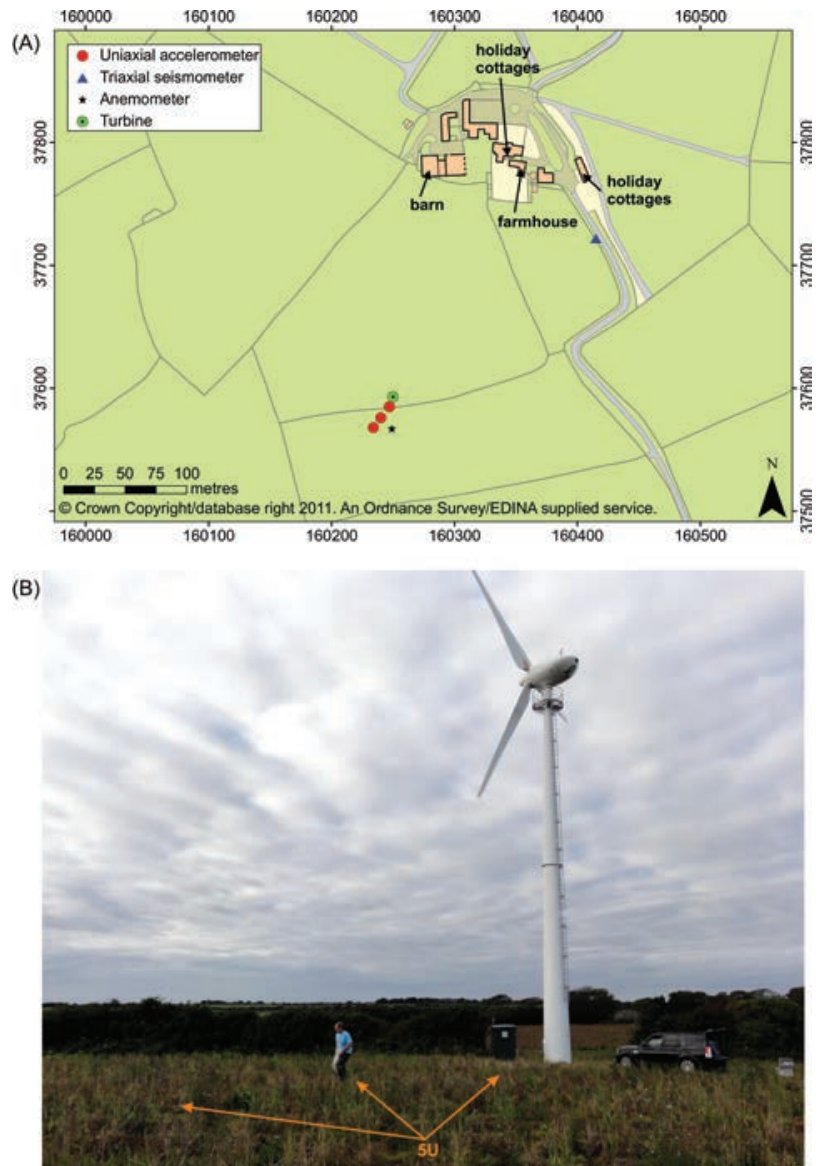

FIGURE 6

The Endurance E-3120 wind turbine test site details. A) The site at Hayle, Cornwall in England. The map shows the location of the sensors in relation to the wind turbine and nearby buildings. B) The Endurance E-3120 wind turbine with the location of the CMG-5U uniaxial sensors highlighted.

This turbine is located on farmland approximately $9 \mathrm{~km}$ east of Kilmarnock in East Ayrshire, Scotland. The site is $2.8 \mathrm{~km}$ north of the main A71 road and $1.5 \mathrm{~km}$ east of the A719. The wind turbine is used to power a farm and is located approximately $200 \mathrm{~m}$ south of the main farm buildings (Fig. 5).

\section{Endurance E-3120: Hayle, Cornwall, England (HAY)}

This is a three-blade small wind turbine with a rated power of 50 $\mathrm{kW}$, at the upper limit of the definition of a small wind turbine. As with the Gaia-Wind 133, the E-3120 has a fixed rotational speed, operating at $43 \mathrm{rpm}$ and a rotor diameter of $19 \mathrm{~m}$. There is an anemometer connected to the upwind side of the nacelle. This is used by the on-board computer system to control the operation of the turbine. The turbine is available on a monopole tower at a height of either $24 \mathrm{~m}$ or $36.5 \mathrm{~m}$. The former was monitored for this study. The turbine sits on a foundation of reinforced concrete, in soil, with a dimension of $6 \mathrm{~m} \times 6 \mathrm{~m} \times 1 \mathrm{~m}$.

Lanyon Farm and holiday cottages are located $4 \mathrm{~km}$ east of 
Hayle in Cornwall. The nearest main road, the A30 is $1.7 \mathrm{~km}$ away. The wind turbine is located in a field belonging to the farm and is used to power the farm and cottages (Fig. 6).

\section{SEISMIC NOISE IN THE PROXIMITY OF SMALL WIND TURBINES}

\section{Spectral Characteristics}

Each of the wind turbines exhibit different spectral characteristics, although the amplitude on the tower is similar (Fig. 7). In general, the average amplitude decreases with distance, indicating that the signal predominantly originates from the turbine, due to the siting and orientation of the sensors. The exception to this is WIG, which is a seismically noisier site and has a higher background noise level on the sensor at $190 \mathrm{~m}$ compared to the other three sites. Additionally, there are also fewer obvious peaks in the spectra for the sensors in the ground furthest away, at all sites.

KIL and MEL both exhibit few peaks in the spectra from the sensors placed in the ground between 10 and $100 \mathrm{~m}$. This data was collected on strong motion accelerometers with a higher noise floor than the seismometer. The flat line spectra visible for these sensors indicates that there is weak ground motion and any signal originating from the turbine has an amplitude too small to be detected on such a sensor. These two turbines additionally display little amplitude above the seismometer noise floor at $190 / 200 \mathrm{~m}$, indicating that the majority of the energy has attenuated by this distance. The other two turbines contain some minor detail in the spectra at all distances. The lack of amplitude may be due to local site conditions, for example soil properties which may present higher attenuation at one site compared to another; or turbine structure, for example the lattice tower may not, given the different lengths of the struts, transfer as much energy as an equivalent height tubular tower.
KIL is the only turbine of the four to have a variable rather than fixed rotor speed. It is a self-regulating turbine with a higher rotor speed at higher wind speeds. This affects the blade passing frequencies, which cause any peaks in the spectra related to the blade passing to shift depending upon the rotor speed.

The spectra for the HAY sensors in the ground at 10, 20 and 30 metres show spurious peaks every $1 \mathrm{~Hz}$. This is thought to be caused by an electrical grounding issue with the digitiser. Taking this into account, the sensors in the ground at each of the sites show few spectral peaks below $4 \mathrm{~Hz}$.

The blade rotation harmonics at multiples of $0.93 \mathrm{~Hz}$ for WIG and MEL and multiples of $0.72 \mathrm{~Hz}$ for HAY are significant in the spectra below $12 \mathrm{~Hz}$, from the data on the tower and at the base (KIL is a variable speed turbine, so has no fixed blade rotation frequency). Below $12 \mathrm{~Hz}$, there are two peaks visible on the tower spectra for MEL at, $2.5 \mathrm{~Hz}$ and $3.5 \mathrm{~Hz}$, which cannot be attributed to blade rotation harmonics. These are not visible in the ground, but are still present on the foundation. These two peaks are likely related to the resonant modes or mechanical mechanism of the turbine.

\section{Signal Identification}

All of the turbines are defined, by the manufacturers, to have a cut-in wind speed of $3.5 \mathrm{~m} / \mathrm{s}$, therefore the wind speed was grouped into less than $2 \mathrm{~m} / \mathrm{s}$ to ensure the wind turbine would not be generating and greater than $3.5 \mathrm{~m} / \mathrm{s}$ for when it is turning. Signals were attributed to the turbine if they were larger on both the tower and foundation than in the ground.

Westwood (2012) describes a multiphysics computational model of a Gaia-Wind 133 tubular tower turbine and calculation of the resonant modes. Using these results it is possible to identify the origin of the frequencies in the on-tower spectrum for


FIGURE 7

Displacement frequency spectra for sensors at a range of distances from each of the four wind turbines, recorded when the turbine was in operation and the wind speed above $3.5 \mathrm{~m} / \mathrm{s}$. 
WIG (Fig. 8). Two types of peaks were identified: peaks associated with the resonant modes of the turbine and those which were linked to the blade rotation rate. Each resonant mode has two frequencies relating to the side-side (swaying) and fore-aft (rocking) motions. The $1^{\text {st }}$ and $2^{\text {nd }}$ resonant modes at $1.1 \mathrm{~Hz}$, $1.9 \mathrm{~Hz}$ and $9.7 \mathrm{~Hz}$ are apparent at both ranges of wind speed. It is therefore possible that these frequencies could transfer into the ground at wind speeds less than $2 \mathrm{~m} / \mathrm{s}$, though at much lower

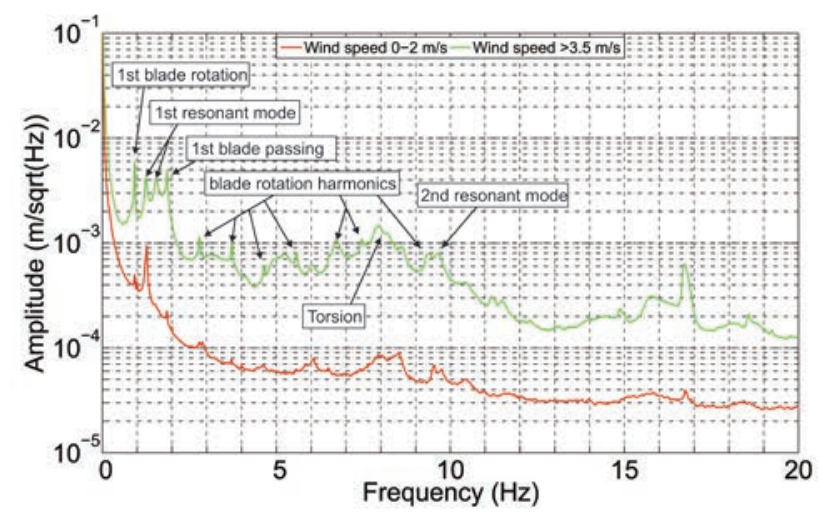

FIGURE 8

An annotated displacement frequency spectra using data recorded on the tower of the Gaia-Wind 133 tubular tower turbine at low $(<2 \mathrm{~m} / \mathrm{s})$ and high $(>3.5 \mathrm{~m} / \mathrm{s})$ wind speeds.

TABLE 2

Frequency peaks visible in the spectra for the three fixed speed turbines seen on the tower and the foundation. Top: the rotation frequency harmonics which decrease significantly in amplitude or are not discernible at low wind speeds. Bottom: The resonant modes of the structure which are significant through all wind speeds.

\begin{tabular}{|c|c|c|}
\hline \multirow[t]{2}{*}{ Comments } & \multicolumn{2}{|c|}{ Approx. frequency at wind speeds $>3.5 \mathrm{~m} / \mathrm{s}(\mathrm{Hz})$} \\
\hline & MEL and WIG & HAY \\
\hline Rotation frequency & 0.93 & 0.7 \\
\hline $2^{\text {nd }}$ harmonic (blade passing - MEL and WIG) & 1.85 & 1.4 \\
\hline $3^{\text {rd }}$ harmonic (blade passing - HAY) & 2.8 & 2.1 \\
\hline $4^{\text {th }}$ harmonic & 3.7 & 2.9 \\
\hline $5^{\text {th }}$ harmonic & 4.6 & 3.6 \\
\hline $6^{\text {th }}$ harmonic & 5.6 & 4.3 \\
\hline $7^{\text {th }}$ harmonic & 6.7 & 5 \\
\hline $8^{\text {th }}$ harmonic & 7.5 & 5.7 \\
\hline $9^{\text {th }}$ harmonic & 8.4 & 6.5 \\
\hline $10^{\text {th }}$ harmonic & 9.3 & 7 \\
\hline $11^{\text {th }}$ harmonic & 10.2 & 7.9 \\
\hline $12^{\text {th }}$ harmonic & 11.2 & 8.6 \\
\hline \multicolumn{3}{|l|}{ Other higher harmonics are also discernible } \\
\hline \multirow[t]{2}{*}{ Comments } & \multicolumn{2}{|c|}{ Approx. frequency $(\mathrm{Hz})$} \\
\hline & MEL & HAY \\
\hline $1^{\text {st }}$ resonant frequency (both variation identified for WIG) & 2.5 & 1.1 \\
\hline $2^{\text {nd }}$ resonant frequency (very close to the blade passing frequency for HAY) & 3.2 & 2.1 \\
\hline
\end{tabular}

amplitudes. For the other two fixed speed turbines (MEL and HAY) the two types of peaks were discriminated between by comparing the spectra at both of the above wind speed ranges and the calculation of the expected blade rotation rate. Table 2 summarises the key frequencies visible in the spectra and their sources for each of the fixed speed turbines.

The varying rotation rate of KIL leads to shifting frequency peaks within the spectra for the blade passing frequency. These peaks increase in frequency as the rotation rate (and wind speed) increase. This agrees with the findings observed by Schofield (2002) for larger variable speed wind turbines. The turbine operates a self-regulating blade bending which stabilises the frequency and amplitude. There are far fewer peaks visible in the spectra for this turbine than the other three (Fig. 7).

\section{WIND SPEED AND AMPLITUDE}

Spectra were calculated over $0.5 \mathrm{~m} / \mathrm{s}$ wind speed intervals (Fig. 9) in order to observe frequency peaks visible throughout the full range of wind speeds. The spectra indicate a gradual increase in amplitude with wind speed both on the tower and foundation, up to a speed where the spectra each start to overlap each other. There is also a significant decrease in amplitude from the tower to foundation

A selection of peaks from Table 2 (highlighted in Fig. 9) was used to observe the relationship between seismic amplitude and wind speed (Fig. 10) using a linear regression calculation. To 

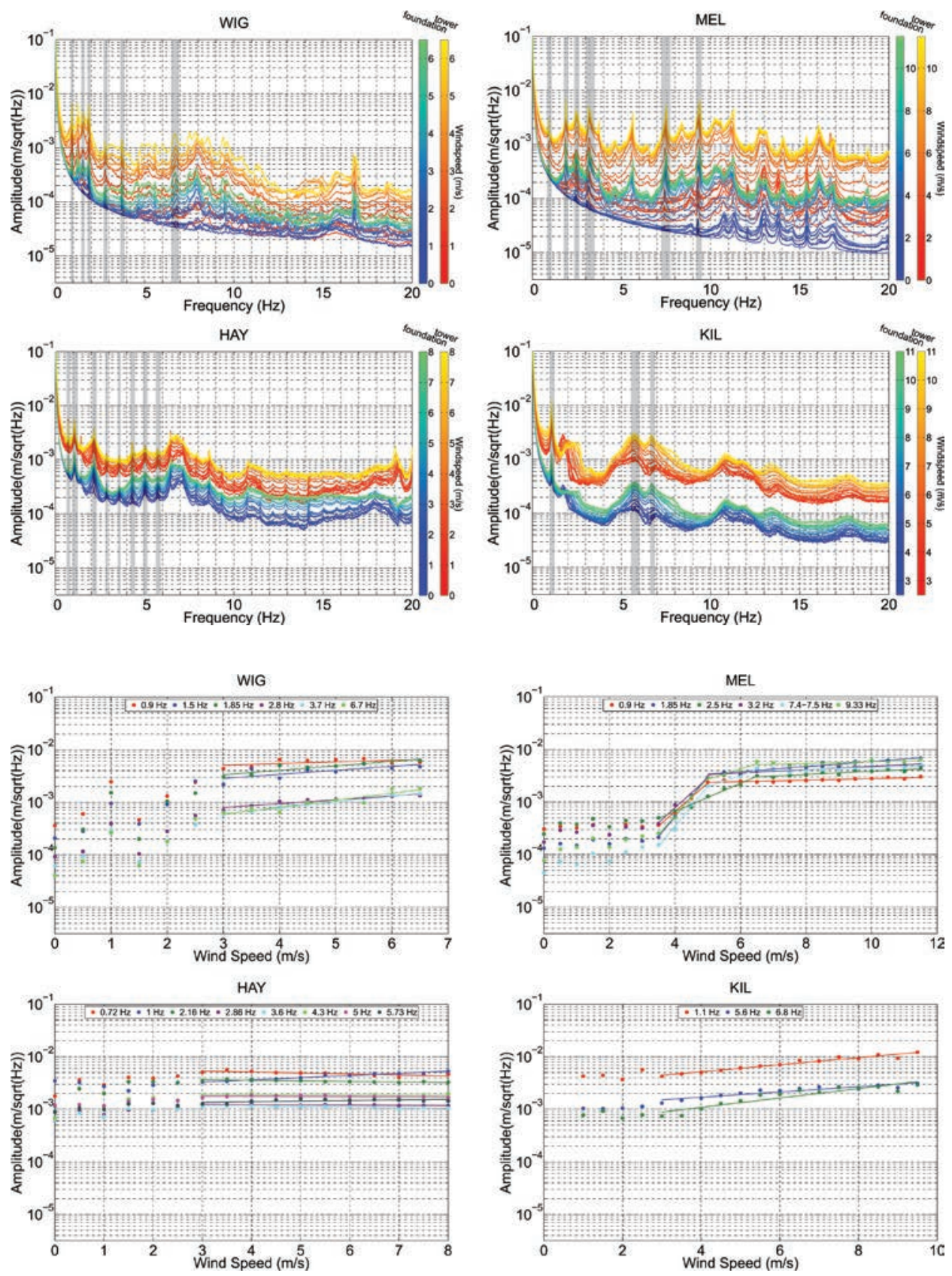

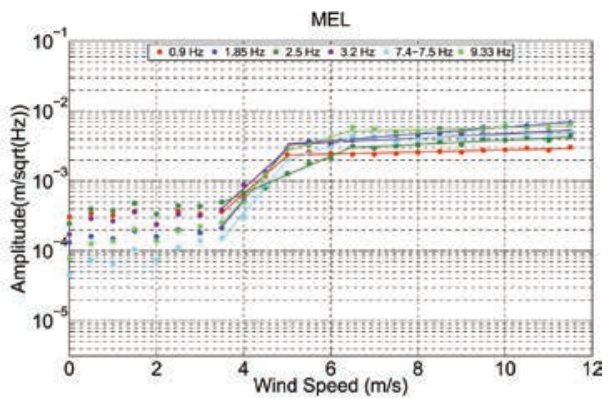

KIL

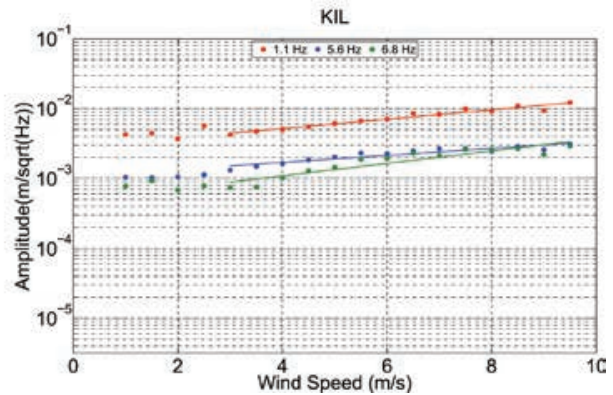

FIGURE 9

The spectra calculated over $0.5 \mathrm{~m} / \mathrm{s}$ ranges from data recorded on the tower (red to orange) and on the foundation (blue to green). The highlighted frequencies are those used for the wind speed analysis.

\section{FIGURE 10}

The relationship between displacement seismic amplitude recorded on the tower and wind speed for each of the four turbines. ensure that the turbine was operational, only wind speeds greater than $2.5 \mathrm{~m} / \mathrm{s}$ were included. Both WIG and HAY show two distinct groups of frequencies. The lower amplitude group contains frequencies which are harmonics of the higher amplitude group. Both turbines have a resonant mode frequency in the higher amplitude group. For HAY, this frequency displays a slightly different gradient, compared to the blade rotation harmonics which are almost constant, whereas for WIG it is the intercept which is distinctly different.

MEL presents a more complicated relationship between wind speed and amplitude, which is most likely due to the lattice struc- ture resonating differently to the tubular towers. The $1^{\text {st }}$ blade rotation and blade passing frequencies show a relationship with a change of gradient occurring at $5 \mathrm{~m} / \mathrm{s}$. The two frequencies which are not associated with the blades also contain a change in gradient, although for $2.5 \mathrm{~Hz}$, this occurs at a different wind speed. The blade rotation harmonics at $7.5 \mathrm{~Hz}$ and $9.3 \mathrm{~Hz}\left(8^{\text {th }}\right.$ and $10^{\text {th }}$ harmonics respectively) present two changes in gradient; one at $5 \mathrm{~m} / \mathrm{s}$ and the second at $6.5 \mathrm{~m} / \mathrm{s}$. These match with the wind speeds of the gradient changes for the other frequencies. These relationships are summarised in Table 3 which shows the significant differences between the tubular tower turbines and the lattice. 
TABLE 3

The equations for calculating seismic amplitude on the tower, with respect to wind speed (w), at HAY, WIG and MEL, for a range of frequencies. The blue rows indicate the fundamental blade rotational and blade passing frequencies, the pink rows are harmonics of these and the green rows, structural resonant frequencies, not related to the blade rotation frequencies.

\begin{tabular}{lc}
\hline HAY & \\
\hline Frequency $(\mathbf{H z})$ & Seismic amplitude on the tower \\
\hline & $\boldsymbol{w}>\mathbf{2 . 5}$ \\
\hline 0.72 & $0.005 e^{-0.2 w}$ \\
1 & $0.0025 e^{-0.09 w}$ \\
2.16 & $0.004 e^{-0.01 w}$ \\
2.86 & $0.001 e^{-0.01 w}$ \\
3.6 & $0.001 e^{-0.1 w}$ \\
4.3 & $0.002 e^{0.1 w}$ \\
5 & $0.002 e^{0.1 w}$ \\
5.73 & $0.001 e^{0.03 w}$ \\
\hline
\end{tabular}

\begin{tabular}{lc}
\hline WIG & \\
\hline Frequency $(\mathbf{H z})$ & Seismic amplitude on the tower \\
\hline & $\boldsymbol{w}>\mathbf{2 . 5}$ \\
\hline 0.9 & $0.041 e^{0.07 w}$ \\
1.5 & $0.017 e^{0.18 w}$ \\
1.85 & $0.018^{0.19 w}$ \\
2.8 & $0.0005 e^{0.17 w}$ \\
3.7 & $0.0003^{0.25 w}$ \\
6.7 & $0.0002^{0.31 w}$ \\
\hline
\end{tabular}

\begin{tabular}{|c|c|c|c|c|c|}
\hline \multicolumn{6}{|l|}{ MEL } \\
\hline \multirow[t]{2}{*}{ Frequency $(\mathrm{Hz})$} & \multicolumn{5}{|c|}{ Seismic amplitude on the tower } \\
\hline & $3.5<w<6.5$ & $3.5<w<5$ & $5<w<6.5$ & $w>5$ & $w>6.5$ \\
\hline 0.9 & & $4.5 \times 10^{-6} e^{1.3 w}$ & & $2 \times 10^{-3} e^{0.03 w}$ & \\
\hline 1.85 & & $0.5 \times 10^{-6} e^{1.8 w}$ & & $2 \times 10^{-3} e^{0.1 w}$ & \\
\hline 2.5 & $57 \times 10^{-6} e^{0.6 w}$ & & & & $2 \times 10^{-3} e^{0.07 w}$ \\
\hline 3.2 & & $4.2 \times 10-6 e^{1.3 w}$ & & $2 \times 10^{-3} e^{0.1 w}$ & \\
\hline 7.4-7.5 & & $0.3 \times 10^{-6} e^{1.8 w}$ & $15 \times 10^{-3} e^{0.5 w}$ & & $3 \times 10^{-3} e^{0.05 w}$ \\
\hline 9.33 & & $0.8 \times 10^{-6} e^{1.6 w}$ & $28 \times 10^{-3} e^{0.5 w}$ & & $4 \times 10^{-3} e^{0.03 w}$ \\
\hline
\end{tabular}

This demonstrates that each small wind turbine generates different frequencies and amplitudes with respect to wind speed and that there is no single rule which applies to all small wind turbines. Additionally, the relationship between wind speed and amplitude for large wind turbines, as defined by Styles et al. (2005), Schofield (2002) and Saccorotti et al. (2011) does not appear to apply to small wind turbines.

\section{Tower to Foundation Relationships}

Using the same frequencies as for the wind speed analysis, the relationship between seismic amplitude $\left(S_{x}\right)$ on the tower and on the foundation $\left(S_{y}\right)$ can be obtained (Fig. 11). Each turbine demonstrates a strong positive relationship:

$$
\begin{array}{ll}
\text { WIG } & S_{y}=0.09 S_{x}^{0.9} \\
\text { MEL } & S_{y}=0.19 S_{x}^{0.9} \\
\text { HAY } & S_{y}=0.04 S_{x}^{0.75} \\
\text { KIL } & S_{y}=0.04 S_{x}^{0.8}
\end{array}
$$

The coefficients of determination are 0.97 (WIG), 0.89 (MEL), 0.95 (HAY) and 0.998 (KIL). This indicates that the predicted amplitude on the foundation, using the amplitude from the tower, is a good fit to the observed data.
Tower to Ground and Foundation to Ground Relationships A similar analysis was attempted for the relationship between the amplitude on the tower and in the ground at 190/200 $\mathrm{m}$ and also between the amplitude on the foundation and in the ground at 190/200 m. However, there are not enough discernible peaks in the spectra from the seismometer to perform a detailed and thorough analysis.

\section{CONCLUSIONS}

This study set out with the aim of determining whether small wind turbines generate vibrations at frequencies in the $4-5 \mathrm{~Hz}$ band which could be detrimental to the listening capabilities of EKA. The vibrations from four small wind turbines were measured using a combination of sensors attached to the tower and at distances of up to $200 \mathrm{~m}$ from the turbine.

The results demonstrate that vibrations from the turbines are transferred into the ground and propagate away from the turbine. However, the spectral content of the signal is specific to each turbine, although, each has noticeable peaks in the $4-5 \mathrm{~Hz}$ band which is critical for EKA. Identification of the source of specific frequencies to the blade rotation, its harmonics and to the resonant frequencies of the turbine showed that at low wind speeds the resonant frequencies can be observed on the tower and foun- 

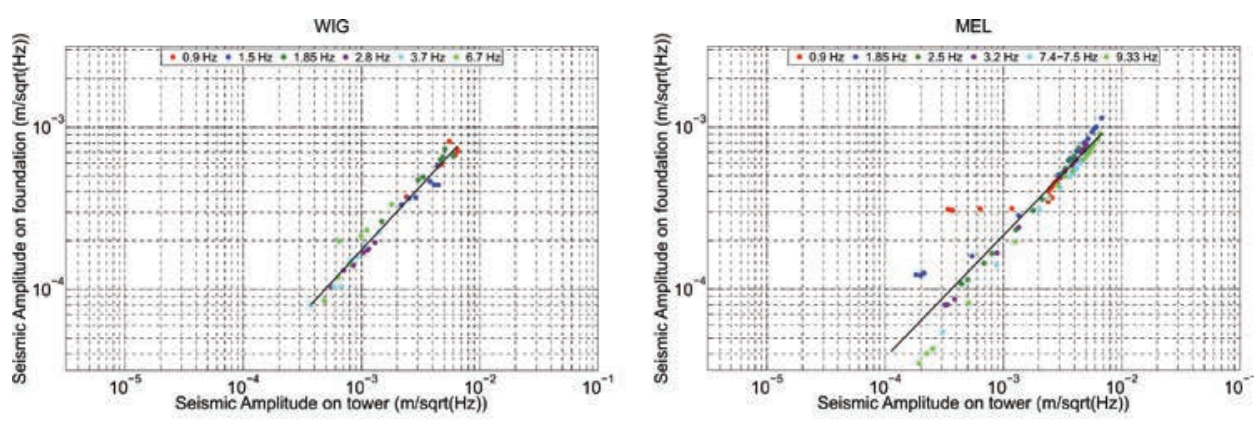

\section{FIGURE 11}

The relationship between displacement seismic amplitude recorded on the tower and the foundation.
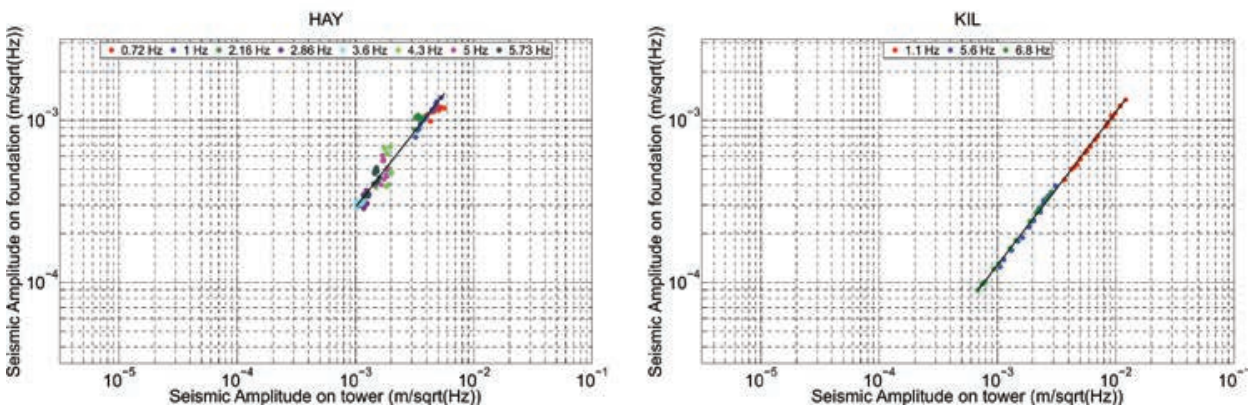

dation. The decrease in amplitude from the tower to the foundation has been shown to fit a power relationship, which is different for each make of turbine. At $200 \mathrm{~m}$, the signals from the lower power, shorter turbines (MEL, WIG and KIL) are less discernible in the spectra. The height of the towers and different foundations are likely to affect the frequencies that are transferred into the ground. This, together with local site conditions, may affect the propagation and power of the signal; for example soil properties may present higher attenuation at one site compared to another.

The sensors in this study were all deployed in the near-field. Assuming that attenuation is higher in the near-field than the farfield, then from the results at $200 \mathrm{~m}$ it is likely that the amplitude will decrease quickly enough such that the far-field signal will be negligible.

An analysis of the relationship between wind speed and seismic amplitude on the turbine showed that the power-law defined for large turbines in previous studies does not hold for small turbines. The relationship between wind speed and amplitude is individual to each wind turbine and the frequency band of interest, although each fits an exponential relationship.

Based on the findings of this work, it is unlikely that one common vibration model, similar to that derived by Styles et al. (2005) for large wind turbines, can be derived for all small turbines and each type may well need to be treated on an individual basis.

One of the main limitations to this study is the location of the sensors, further studies carried out on small wind turbines could be used to assess the vibrations at greater distances and in the far-field. This study only used one anemometer to record wind speed. Recording wind speed data at two or more heights for any future studies would enable a more accurate calculation of the wind shear component. Additionally, advanced signal processing techniques, such as wavelet analysis, may provide further infor- mation of the resonant modes of the turbines. Further studies of medium sized wind turbines $(>50 \mathrm{~kW}$ and $<500 \mathrm{~kW}$ ) will allow a more complete picture of the vibrations from wind turbines to be observed in order to determine if a model similar to that derived by Styles et al. (2005) can be used to predict the amplitude of vibrations from turbines of all heights and power. In the meantime, based on the findings in this paper, small wind turbines in the vicinity of EKA could be considered on an individual basis, prior to planning being granted.

\section{ACKNOWLEDGEMENTS}

We would like to thank Gaia-Wind, Endurance Wind Power, AWE Blacknest and SEIS-UK for their support in this project. We are also very grateful to the landowners for allowing us access to the turbines and the deployment of sensors. Thanks also go to Malcolm Wright and Johnathan Green for their fieldwork assistance, to Sangeeta Khorana for her helpful feedback and to the reviewers for their suggestions that have ultimately improved the paper. This paper draws on $\mathrm{PhD}$ research, entitled "Seismic monitoring and multiphysics modelling of groundborne vibrations from small wind turbines," which was jointly funded by the Engineering and Physical Sciences Research Council (Grants EP/P502535/1 and EP/P503981/1) and Keele University Acorn research grant.

\section{REFERENCES}

Bowers D. 2004. Effects of Known and Foreseeable Noise Interference on Seismic Arrays. Report No. 763/04. AWE.

Brisbourne A., Lane V., Hawthorn D. and Horleston A. 2013. 6TD \& ESPD Field Methods. SEIS-UK. http://www.le.ac.uk/seis-uk/ downloads/6TD_esp_seisuk_manual.pdf

de Beer E. 2013. Assessment of low-frequency noise due to wind-turbines in relation to low-frequency background noise. INTER-NOISE 
and NOISE-CON Congress and Conference Proceedings, Innsbuck, Austria, Expanded Abstracts 3795-3803

Díaz O. and Suárez L.E. 2013. Seismic Analysis of Wind Turbines. Earthquake Spectra In-Press, doi: 10.1193/123011EQS316M

Dijkstra M. and Kerkers T. 2011. Continuous noise monitoring of wind turbines. $4^{\text {th }}$ International Conference of Wind Turbine Noise, Rome, Italy, Expanded Abstracts.

Elliot J., Bowers D. and Selby N.D. 2004. Correlations between seismic noise and wind speeds and directions at the Eskdalemuir array. AWE.

England R.J.E. 2007. Microseismic and Infrasound Monitoring of Low Frequency Noise and Vibration from Windfarms. $\mathrm{PhD}$ Thesis. Keele University.

Fiori I. , Giordano L., Hild S., Losurdo G., Marchetti E., Mayer G. and Paoletti F. 2009. A Study of the Seismic Disturbance Produced by the Wind Park Near the Gravitational Wave Detector. Third International Meeting on Wind Turbine Noise, Aalborg, Denmark, Expanded Abstracts.

Gsänger S. and 2013. Small Wind World Report 2013. World Wind Energy Association, Bonn, Germany. http://www.wwindea.org/ webimages/SWWR_summary.pdf

Guarnaccia C., Lenza T.L.L. and Quartieri J. 2011. On the Propagation Model of Wind Farm Noise. $4^{\text {th }}$ International Conference of Wind Turbine Noise, Rome, Italy, Expanded Abstracts

Jakobsen J. 2005. Infrasound Emission from Wind Turbines. Journal of Low Frequency Noise, Vibration and Active Control 24(3), 145-155. doi: 10.1260/026309205775374451

Larsson C. and Öhlund O. 2014. Amplitude modulation of sound from wind turbines under various meteorological conditions. The Journal of the Acoustical Society of America 135(1), 67-73. doi: $10.1121 / 1.4836135$

Legerton M.L., Manley D.M.J.P., Sargent J.W., Snow D.J. and Styles P. 1996. Low frequency noise and vibration levels at a modern wind farm. Proceedings of Inter-Noise 96, Liverpool, Expanded Abstracts 459-462

Liu W.Y. 2013. The vibration analysis of wind turbine blade-cabintower coupling system. Engineering Structures 56, 954-957. doi: 10.1016/j.engstruct.2013.06.008

Manwell J.F., McGowan J.G. and Rogers A.L. 2009. Wind Energy Explained: Theory, Design and Application, $2^{\text {nd }}$ edn. John Wiley and Sons Ltd.

Mollasalehi E., Sun Q. and Wood D. 2013. Contribution of Small Wind Turbine Structural Vibration to Noise Emission. Energies 6(8), 36693691. doi: 10.3390/en6083669

Møller H. and Pedersen C.S. 2011. Low-frequency noise from large wind turbines. The Journal of the Acoustical Society of America 129(6), 3727-3744. doi: 10.1121/1.3543957

Pedersen E. and Waye K.P. 2008. Wind turbines - low level noise sources interfering with restoration? Environmental Research Letters 3(1),
015002. doi: 10.1088/1748-9326/3/1/015002

Peterson J. 1993. Observations and modelling of seismic background noise. Open-File Report 93-322. US Department of Interior Geological Survey.

Saccorotti G., Piccinini D., Cauchie L. and Fiori I. 2011. Seismic Noise by Wind Farms: A Case Study from the Virgo Gravitational Wave Observatory, Italy. Bulletin of the Seismological Society 101(2), 568578. doi: $10.1785 / 0120100203$

Schofield R. 2002. Seismic Measurements at the Stateline Wind Project. LIGO T020104-00-Z. PDF available from: http://www.ligo.caltech. edu/docs/T/T020104 - 00.pdf

Skrzypiński W. and Gaunaa M. 2014. Wind turbine blade vibration at standstill conditions -the effect of imposing lag on the aerodynamic response of an elastically mounted airfoil. Wind Energy 17, doi: $10.1002 /$ we 1712

Styles P., Stimpson I., Toon S., England R. and Wright M. 2005. Microseismic and Infrasound Monitoring of Low Frequency Noise and Vibrations from Windfarms. Keele University. PDF available from: http://www.keele.ac.uk/geophysics/appliedseismology/wind

Taddei F. and Meskouris K. 2014. Seismic Analysis of Onshore Wind Turbine Including Soil-structure Interaction Effects. In: Seismic Design of Industrial Facilities, pp.511-22.

Taylor J., Eastwick C., Lawrence C. and Wilson R. 2013. Noise levels and noise perception from small and micro wind turbines. Renewable Energy 55, 120-127. doi: 10.1016/j.renene.2012.11.031

Truscott J.R. 1964. The Eskdalemuir Seismological Station. Geophysical Journal International 9(1), 59-68. doi: 10.1111/j.1365-246X.1964. tb06314.x

Welch P. 1967. The Use of Fast Fourier Transform for the Estimation of Power Spectra: A Method Based on Time-Averaging Over Short, Modified Periodograms. IEEE Transactions on Audio and Electroacoustics 15(2), 70-73. doi: 10.1109/TAU.1967.1161901

Westwood R.F. 2012. Seismic monitoring and multiphysics modelling of ground-borne vibrations from small wind turbines. $\mathrm{PhD}$ thesis. Keele University.

Yang B. and Sun D. 2013. Testing, inspecting and monitoring technologies for wind turbine blades: A survey. Renewable and Sustainable Energy Reviews 22, 515-526. doi: 10.1016/j.rser.2012.12.056

Zhang Z., Verma A. and Kusiak A. 2012. Fault Analysis and Condition Monitoring of the Wind Turbine Gearbox. IEEE Transaction on Energy Conversion 27(2), 526-535. doi: 10.1109/TEC.2012.2189887

Zhou H.F., Dou H.Y., Qin L.Z., Chen Y., Ni Y.Q. and Ko J.M. 2014. A review of full-scale structural testing of wind turbine blades. Renewable and Sustainable Energy Reviews 33, 177-187. doi: 10.1016/j.rser.2014.01.087 